\title{
POLÍTICAS PÚBLICAS PARA AGRICULTURA FAMILIAR: AVALIAÇÃO DO ACESSO AO PRONAF ENTRE FEIRANTES DE UMA ASSOCIAÇÃO DE AGRICULTORES EM ABAETETUBA, PARÁ
}

Public policies for family farmer: Evaluation of access to PRONAF among farmers of an association of farmers in Abaetetuba, Pará

Políticas públicas para la agricultura familiar: Evaluación del acceso al PRONAF entre los agricultores de una asociación de agricultores en Abaetetuba, Pará

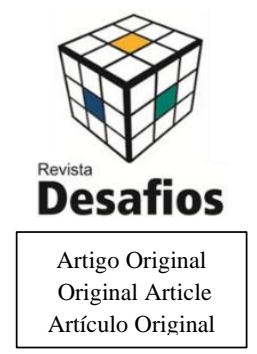

\section{Walbert Cardoso Pimentel ${ }^{* 1}$, Livio Sergio Dias Claudino ${ }^{2}$}

${ }^{1}$ Mestrando do Programa de Pós-Graduação em Cidades, Territórios e Identidades, Abaetetuba, Brasil.

${ }^{2}$ Professor Doutor. do Programa de Pós-Graduação em Cidades, Territórios e Identidades, Universidade Federal do Pará, Abaetetuba, Brasil.

*Correspondência: Universidade Federal do Pará, Programa de Pós-Graduação em Cidades, Territórios e Identidades, Ramal Manoel de Abreu, S/n - Mutirão, Abaetetuba - Pará, Brasil. CEP: 68440-000 e-mail walbertcpimentel@hotmail.com.

\section{RESUMO}

Esta pesquisa analisou as condições de acesso às políticas públicas, com enfoque no acesso ao Programa Nacional de Fortalecimento da Agricultura Familiar (PRONAF) entre agricultores familiares no município de Abaetetuba Pará, tendo como grupo focal os integrantes de uma associação de agricultores familiares feirantes. Foram entrevistadas 30 pessoas, por meio de aplicação de questionários, diretamente aos feirantes; e entrevistas com agentes públicos. As questões buscavam um levantamento de perfil socioeconômico e os fatores que limitavam acessar o financiamento. Foi realizada também pesquisa documental. Os dados obtidos foram sistematizados em ferramenta de tabelas do Microsoft Excel, agrupados conforme características sociais e econômicas dos feirantes, bem como de suas possíveis relações com os limitantes ao crédito. Para análises, foram separados em dois grupos: aqueles que acessaram e os que que não acessaram o crédito. Como principais resultados, detectamos que $50 \%$ da amostragem obteve acesso ao crédito PRONAF, e que entre os fatores que condicionam o acesso ao crédito há algumas predominâncias, que destacamos: o tamanho da terra, o gênero e a posse do Documento de Aptidão ao Pronaf (DAP). Palavras-chave: financiamento público; crédito rural; nordeste paraense.

\section{ABSTRACT}

This research analyzed the conditions of access to public policies, focusing on access to the National Program for Strengthening Family Farming (PRONAF) among family farmers in the municipality of Abaetetuba-Para, with the focus group being members of an association of family farmers. 30 people were interviewed, through the application of questionnaires, directly to the marketers; and interviews with public servers. The questions sought a survey of the socioeconomic profile and the factors that limited access to finance. Documentary research was also carried out. The data obtained were systematized using a Microsoft Excel table tool, grouped according to the social and economic characteristics of marketers, as well as their possible relationships with credit limiters. For analysis, they were separated into two groups: those who accessed and those who did not access the credit. As main results, we found that $50 \%$ of the sample obtained access to PRONAF credit, and that among the factors that condition access to credit there are some predominances, which we highlight: the size of the land, the gender and the possession of the Pronaf Aptitude Document.

Keywords: public funding; rural credit; northeast paraense. 


\section{RESUMEN}

Esta investigación analizó las condiciones de acceso a las políticas públicas, centrándose en el acceso al Programa Nacional para el Fortalecimiento de la Agricultura Familiar (PRONAF) entre los agricultores familiares en el municipio de Abaetetuba - Pará, con el grupo focal como miembros de una asociación de agricultores familiares. 30 personas fueron entrevistadas, mediante la aplicación de cuestionarios, directamente a los vendedores; y entrevistas con funcionarios públicos. Las preguntas buscaban una encuesta sobre el perfil socioeconómico y los factores que limitaban el acceso a las finanzas. También se realizó investigación documental. Los datos obtenidos se sistematizaron utilizando una herramienta de tabla de Microsoft Excel, agrupada de acuerdo con las características sociales y económicas de los vendedores, así como sus posibles relaciones con los limitadores de crédito. Para el análisis, se separaron en dos grupos: los que accedieron y los que no accedieron al crédito. Como resultados principales, encontramos que el $50 \%$ de la muestra obtuvo acceso al crédito PRONAF, y que entre los factores que condicionan el acceso al crédito hay algunas predominancias, que destacamos: el tamaño de la tierra, el género y la posesión del Documento de Aptitud de Pronaf (SALTO).

Descriptores: financiamiento público; crédito rural; noreste de Pará.

\section{INTRODUÇÃO}

Os debates sobre políticas públicas para o meio rural ganharam notoriedade nas últimas décadas, especialmente pela inclusão de agricultores familiares e diversos grupos específicas, como comunidades tradicionais, entre outras, tendo como ponto comum o gerenciamento governamental. Nesse entendimento, tendem à conformidade com os modelos de cada sociedade que os constituem. Tendo em vista que as políticas são de cunho regulatório, ficam sujeitas a avaliações e análises, podendo haver alterações em suas estruturas, de forma a atingir uma maior eficácia de seus objetivos, sejam estes na própria efetivação da política ou no controle do programa pelo governo que a implantou. Conforme destaca Souza:

Pode-se, então, resumir política pública como o campo do conhecimento que busca, ao mesmo tempo, "colocar o governo em ação" e/ou analisar essa ação (variável independente) e, quando necessário, propor mudanças no rumo ou curso dessas ações (variável dependente). A formulação de políticas públicas constitui-se no estágio em que os governos democráticos traduzem seus propósitos e plataformas eleitorais em programas e ações que produzirão resultados ou mudanças no mundo real (Souza, 2006, p. 26).

Levando em consideração que as instituições do Estado sofrem influências frente à efetividade de políticas públicas, pontua-se a importância da organização e mobilização dos movimentos sociais frente ao acesso às mesmas, seja na implantação de novas políticas ou na reformulação das políticas vigentes, contribuindo para uma maior adequação às particularidades das camadas sociais e ao atendimento de um maior número de interesses.

Um dos exemplos, aqui analisados, é o Programa Nacional de Fortalecimento da Agricultura Familiar (PRONAF), que foi e é marcado por adaptações ao longo do tempo, de modo a atender às capilaridades da agricultura familiar. $\mathrm{O}$ mesmo surgiu do Programa de Valorização da Pequena produção Rural (PROVAV), fruto das pressões dos movimentos sociais, sendo o embrião para a primeira e mais importante política institucional para os agricultores familiares (Schneider, Mattei, Cazella, 2004). As inúmeras modificações levaram à institucionalização, em 1996, com o Decreto no 1.946.

Tendo em vista a importância social e política da agricultura familiar no município de Abaetetuba e a disponibilidade de programas de fomentos $\mathrm{e}$ incentivos para esse grupo, indagamos os possíveis motivos que levam a uma quantidade expressiva de agricultores a não acessarem os subsídios para aplicar 
em seu estabelecimento. Grisa e Schneider (2014, p. 126) indicam que "historicamente, a agricultura familiar ou "os pequenos agricultores" - como eram denominados até cerca os anos 1990 - sempre estiveram às margens das ações do Estado brasileiro, não raro incrementando sua fragilidade diante das opções de desenvolvimento perseguidas no país”.

Tendo por direção essas constatações, o texto analisa especificamente o acesso ao PRONAF, em unidades familiares presentes no município de Abaetetuba, nordeste do estado do Pará, mais especificamente entre os agricultores da Associação dos Feirantes da Feira da Agricultura Familiar de Abaetetuba (AFAFA). O foco é diagnosticar e analisar os empecilhos ao acesso à essa política pública, apresentando dados quantitativos e qualitativos sobre os feirantes e também acerca dos contratos e valores do programa na escala nacional, regional e municipal.

Atualmente, os canais de comercialização institucionais para agricultores se configuram com a presença de uma variedade de programas, principalmente em torno da matriz do Programa de Aquisição de Alimentos (PAA) e do Programa Nacional de Alimentação Escolar (PNAE), que estiveram presentes e em vigor no município de Abaetetuba, Pará, em 2018 e 2019.

A partir de novas concepções sobre a importância da agricultura familiar ao fornecimento de alimentação de qualidade, seja para o mercado institucional ou fora dele, têm sido notórias mobilizações em prol da garantia do acesso ao direito a esses fomentos. Todos os acessos a financiamento dependem diretamente de alguns procedimentos burocráticos, com documentos comprobatórios, uns mais rigorosos que outros, como a exemplo da Declaração de Aptidão ao PRONAF (DAP), por meio da Lei No 11.326 , de julho de 2006, que está passando por uma transição para o Cadastro Nacional da Agricultura Familiar (CAF).

Tais procedimentos podem se tornar impeditivos, provocando indeferimento daqueles agricultores que não atendam aos requisitos documentais. Há ainda a questão mais sutil do acesso às informações, que limitam a compreensão e também a participação nos programas.

Dessa forma, esta pesquisa tem como objetivo geral analisar as condições de acesso ao PRONAF, identificando principalmente os fatores que dificultam o acesso dos agricultores familiares, tendo como grupo focal agricultores associados da AFAFA. Para tanto, os objetivos específicos são: a) avaliar o funcionamento do PRONAF de uma maneira geral, seus critérios, suas características e faixas; b) Revisar, na literatura, os principais limitantes ao acesso; c) realizar uma análise socioeconômica e produtiva de uma amostragem de agricultores da feira do agricultor familiar de Abaetetuba, identificando suas características produtivas e de acesso ao PRONAF.

\section{MATERIAIS E MÉTODOS}

A pesquisa se desenvolveu, inicialmente, a partir de coleta de dados por meio de pesquisa bibliográfica, em estudos relativos ao PRONAF. Foram realizadas consultas a sites governamentais que abordam sobre o PRONAF, com enfoque nas legislações vigentes e quantitativo de recursos.

A fim de compreender o volume e valores de contratos destinados aos agricultores familiares no município de Abaetetuba, via PRONAF, foi realizada pesquisa na página oficial do Banco Central do Brasil, detalhando os financiamentos aos níveis do estado do Pará e do município de Abaetetuba. O camimho no site foi: Sistema Financeiro Nacional - Crédito Rural Sistema de Operações do Crédito Rural e do Proagro SICOR - Matriz de Dados do Crédito Rural - MDCR 
- quantidade e valor dos contratos por município e região, selecionando janeiro como mês de início e dezembro como mês fim, UF: Pará; Programa: PRONAF - ano de início e ano fim, com o mesmo valor, obedecendo a um período de um ano; Fontes de recursos: todas; Subprograma: todos. Já para a obtenção de dados relativos às especificidades do município de Abaetetuba, foram utilizados dados oficiais disponibilizados no site oficial do Instituto Brasileiro de Geografia e Estatística - IBGE. Como forma complementar, foi necessário um levantamento nas instituições, junto aos técnicos e responsáveis que prestam serviços de Assistência Técnica e Extensão Rural (ATER) para os agricultores.

A pesquisa em campo teve como lócus a feira do agricultor familiar de Abaetetuba, com uma amostragem de 30 agricultores, que são também feirantes. No momento da pesquisa, a feira tinha mais de 80 associados, e cerca de 40 feirantes ativos (quer dizer, aqueles que estão efetivamente com bancas vendendo produtos). As entrevistas, com aplicação de questionários semiestruturados, foram realizadas em dias normais de feiras, às sextas e sábados, entre os dias 09 e 20 de outubro de 2018, e também em momentos da assembleia extraordinária que ocorreu no interstício. As entrevistas com agentes públicos aconteceram também nos meses de novembro e dezembro do mesmo ano.

A Feira da Agricultura Familiar de Abaetetuba começou suas atividades em junho de 2016, funcionando em um galpão no Centro da cidade. A mesma foi idealizada por técnicos de empresas governamentais, principalmente Emater $-\mathrm{Pa}$ e Secretaria Municipal de Agricultura e Abastecimento (SEMAGRI), e conseguiu se estabelecer como importante meio de comercialização dos produtos da agricultura familiar (Claudino et al., 2017).
Trata-se de um grupo que há mais de 2 anos (desde meados de 2016) está mais próximo do poder público municipal, pois são integrantes da associação, que fica situada em um prédio que divide espaço com a Empresa de Assistência Técnica e Extensão Rural (Emater- $\mathrm{Pa})$.

Já em campo, por meio dos dados coletados, foi possível identificar as características relacionadas aos agricultores da AFAFA, como o gênero, número de membros dependentes por família, posse ou não de DAP ou CAF, grau de escolaridade, idade, formas de aquisição do lote, tempo que de reside no lote, canais de venda, número de atividades, extensão das propriedades, entre outras informações no questionário. Com os dados sistematizados, juntamente com as informações referentes ao acesso ou não ao PRONAF, foi possível analisar possíveis predominâncias, dividindo o grupo em duas categorias: Acesso e Não-acesso, indicando possíveis condicionantes ao acesso.

\section{RESULTADOS E DISCUSSÃO}

Em termos numéricos, conforme dados disponibilizados no site oficial do Banco Central do Brasil, o montante acessado a nível nacional no ano de 2013, a partir do PRONAF, em valores de moeda real, foi de $\mathrm{R} \$ 139.433 .044 .595,97$, sendo que desse total, $\mathrm{R}$ \$ 5.874.193.212,07 foram distribuídos entre os estados da região Norte. Já em 2017, o volume nacional foi de $\mathrm{R} \$ 161.926 .583 .226$, sendo destinados $\mathrm{R} \$$ 7.852.790.204,73 para a região Norte. No Estado do Pará, em 2013, foi acessado o valor total de R\$ 382.893.723,36, por meio de 35.247 contratos, e em 2017, o volume caiu para $\mathrm{R} \$ 236.490 .808,48$, em pouco menos da metade dos contratos (12.455).

Já na cidade em análises, Abaetetuba, em 2013 foram acessados R $\$ 2.457 .917,86$, distribuídos em 85 contratos na forma de custeio no setor agrícola e 441 
contratos em forma de investimento (destes, 419 foram aplicados no setor agrícola e 22 no setor da pecuária), totalizando 526 contratos efetivados no município de Abaetetuba. E em 2017, o valor acessado foi de R\$ 1.195.213,73, em 66 projetos. Vale destacar que o Censo Agropecuário de 2017 apontou um número de 9.410 estabelecimentos agropecuários classificados como agricultura familiar no município de Abaetetuba-Pará (IBGE, 2017).

De maneira geral, pode-se constatar que o volume total de recursos e o número de projetos reduziu, entre os anos 2013 e 2016/2017, na escala estadual e no município em questão. Segundo Araújo e Vieira-Filho (2018, p. 10), a disponibilização de recursos foi desequilibrada no último período "muito provavelmente resultado da redução dos gastos públicos do governo federal com programas e políticas públicas após a recente crise econômica brasileira.”. De fato, ao mesmo tempo em que decresceu o volume de recursos, reduziu-se o número de contratos, porém, o valor médio de cada contrato aumentou. Por exemplo, em 2013 o valor médio acessado foi de R\$ 4.672,84 em Abaetetuba, distribuídos para um total de 526, enquanto que em 2017 foi de R \$ 18.109,29, para um total de 66 projetos financiados.

Já tratando sobre os dados em campo, dos interlocutores, entre os entrevistados, a faixa de idade vai de mais de 20 anos de idade até menos de 70 anos, com uma maior concentração dos que possuem idade de mais de 30 anos até a 60 anos de idade, que quando somados atingem 76\% (23) dos entrevistados. Da amostragem, 56,66\% (17) possuem como grau de escolaridade apenas o ensino fundamental, enquanto que outros $36,66 \%$ (11) possuem o nível médio, e mais $6,66 \%$, possuem formação técnica ou nível superior.

Em relação ao tempo que residem no estabelecimento, apenas $13 \%$ (4) estão há menos de 10 anos. Os demais estão há mais de 10 anos, indo até aqueles (13\%) que estão há mais de 50 anos. Isso indica uma população já bastante estabilizada em termos fundiários, que tendem a investir mais nos espaços de produção.

Em relação à forma de aquisição dos lotes, o maior percentual de agricultores teve acesso por meio de herança, com um número de 25 agricultores, que equivale a $83 \%$ dos entrevistados. Outros 4 (14\%) declararam que tiveram a posse do lote por meio da compra, e apenas 1 agricultor declarou que tem uso da terra concedido por usucapião. Segundo Silva (2015), que avaliou políticas públicas de desenvolvimento rural em Minas Gerais, observa-se a tendência, nos casos de obtenção por relações de parentesco, como heranças, por exemplo, do parcelamento das propriedades ao longo do tempo, acelerando a minifundiarização, fator agravante aos processos de desenvolvimento rural.

A extensão total de terras, somando a amostragem, atingem 214,749 ha, com uma média de 7,15 ha por agricultor. A maioria dos entrevistados (67\%) declarou que possuem áreas menores que 10 ha e, desse total, 95\% possuem áreas inferiores a 5,3 ha. Destaca-se que o Módulo Fiscal no munícipio é de 70 ha. Em trabalho similar, segundo Bezerra e Schlindwein (2016, p. 8), “diferentes autores destacam que um fator limitador para produção agrícola familiar é a pequena área de terra”.

Essa questão da extensão das terras apresentou uma instigante relação quando os agricultores foram separados entre o que acessaram e os que não acessaram o crédito. Do total de entrevistados, 20 (67\%) possuem áreas de até 10 ha; os outros 10 (33\%) possuem lotes maiores que 10 ha. Quando separados nos grupos de Acesso ou Não-acesso, identificamos que dos 20 com áreas menores, apenas 8 acessaram o crédito; por outro lado, dos 10 com áreas maiores, 7 
acessaram o crédito. Isso indica que aqueles com mais capital fundiário tendem a ter mais acesso ao crédito.

A posse de documentos específicos também é tema relevante para compreender o acesso aos créditos. Em nossa amostragem, $63 \%$ do total possuem DAP ou CAF, enquanto outros 37\% nenhuma das duas declarações. Vale lembrar que a DAP é o principal documento para o acesso a qualquer uma das linhas de crédito do PRONAF e mais 15 políticas públicas do Governo Federal, tais como: o Programa Nacional de Alimentação Escolar (PNAE); Programa de Aquisição de Alimentos (PAA), sendo essa ferramenta muito importante para inclusão ou exclusão no pleito de políticas públicas de incremento à agricultura familiar (SEAD, 2018).

Quando analisados os períodos de emissão das DAP, constatamos que $11(36,66 \%)$ agricultores obtiveram posse das declarações no ano de 2018. Conforme Portaria $\mathrm{n}^{\mathrm{o}}$ 523, de 24 de agosto de 2018, em seu Art. 3, a validade para a DAP, a contar da data de emissão, é de 2 anos. Já aqueles que declararam ter posse da DAP entre os períodos de 2011 a 2017, estavam vencidas por ocasião da entrevista, implicando na impossibilidade de acesso aos créditos (Brasil, 2018).

Destaca-se o fato de que, atualmente, para acessar o recurso, é muito relevante ter tais documentos. Em nossa amostragem, dos 15 que acessaram o crédito, 13 possuem a documentação. Segundo entrevista informal, com o então secretário municipal de agricultura (G.F.M., entrevista realizada dia 28 de novembro de 2018), a falta de documentação é um dos principais limitantes de acesso ao PRONAF, pois esbarra na burocracia bancária. A informação foi confirmada pelo técnico da EMATER (entrevista realizada dia 29 de novembro de 2018), que ressaltou que a ausência do Cadastro Ambiental Rural (CAR), e de regularização ambiental estão entre os grandes entraves para acesso ao crédito. A situação pode ser considerada mais agravante quando ponderamos que $o$ grupo dos feirantes é privilegiado por estar mais próximo das instituições que os outros agricultores familiares localizados mais nos interiores do município.

Quando questionados sobre onde obtêm informações sobre o PRONAF, 30\% nos disseram que recebem por intermédio de associações, já outros $17 \%$ declararam que foi por meio da EMATER, 3\% por meio de sindicatos e $3 \%$ por meio da própria comunidade. $\mathrm{O}$ restante, $7 \%$ informam-se por diversos meios e não souberam precisar a origem da informação. Em torno de $40 \%$ dos entrevistados informaram não conhecer o programa e nem suas finalidades.

Estudos de Silva (2015) destacam a necessidade de articulação entre os órgãos institucionais, com intuito de estabelecer parcerias com organismos mais próximos (sobretudo conselhos, prefeituras, EMATER e associações comunitárias), com vistas a formar uma rede local para garantir um arranjo organizacional mais sólido, que os permita alcançar um melhor fluxo de informações, maior capacidade de acesso aos recursos, mais agilidade e capacidade de ação.

As principais atividades executadas pelos agricultores são: produção de farinha de mandioca, criação de frango, criação de abelhas, plantio de hortaliças, cultivo de pimenta do reino, plantios de banana, açaí, abacaxi, maracujá, cupuaçu entre outras. O número de atividades por estabelecimento vai de 1 a 12 atividades. Em nossa amostragem, $40 \%$ dos entrevistados realizam de 7 a 9 atividades no lote para obtenção de renda, e 27\% declararam realizar até 3 atividades no lote, enquanto outros $27 \%$ declararam realizar de 4 a 6 atividades no lote. Outros $6 \%$ de 10 a 12 atividades no lote. 
No que diz respeito à ocupação das terras para uso agrícola, $7(23,3 \%)$ agricultores utiliza de até $25 \%$ do total da propriedade, outros 9 (30\%) declararam que utilizam mais de $25 \%$ até $50 \%$ do total de sua área, enquanto que 4 (13,3\%) utiliza de 50\% a $75 \%$ da propriedade. Do restante, 6 (20\%) trabalham ativamente de $75 \%$ a $100 \%$ da propriedade, e 4 $(13,3 \%)$ dos entrevistados não sabe o tamanho da área que utiliza para atividades na agricultura. Esses números indicam que ainda há áreas que podem ser utilizadas para a agricultura entre feirantes da amostragem.

Para além da feira do agricultor familiar, que os agricultores são associados (AFAFA), alguns fazem a comercialização dos produtos para outros espaços como: feira de Barcarena, feira no Moju, feira de Vila do Conde, feira orgânica em Belém, feira orgânica na Albrás. Outros agricultores destacaram a comercialização de seus produtos em redes de lanchonetes, negociações com marreteiro ou atravessadores, venda direta na propriedade rural, em restaurantes, no comércio local chamado "Feira da beira ou beiradão", para programas do governo federal como, PNAE e PAA. Em números, em torno de $80 \%$ (24) famílias possuem de 1 a 2 canais de comercialização de seus produtos; o restante, $20 \%$ (6) possuem de 3 a 5 canais de comercialização.

As rendas brutas anuais, entre os entrevistados, variaram de $\mathrm{R} \$ 3.360,00$ até $144.000,00$ anuais, com uma média de $\mathrm{R} \$ 35.680,00$, havendo maior concentração nos estratos de rendas anuais que variam de $\mathrm{R} \$ 3.360,00$ a 9.900,00, com um percentual de $26,7 \%$ agricultores, seguido dos que possuem rendas anuais de $\mathrm{R} \$ 10.000,00$ a $\mathrm{R} \$ 1$ 19.900,00, acumulando um percentual de $20 \%$ dos agricultores. Tendo como base as rendas citadas, e os requisitos propostos pelo banco Basa (2018), os mesmos podem ser enquadrados no PRONAF B, para concessão de créditos, pois dispõem de rendas brutas anuais de até $\mathrm{R} \$ 20.000,00$. No outro extremo, identificamos que $10 \%$ da amostragem tem renda anual superior a $\mathrm{R} \$$ $100.000,00$.

Para alguns autores, o PRONAF foi responsável pela elevação da média da renda de agricultores familiares, permitindo o surgimento daquilo que Barros (2015) chama de "nova classe média" da agricultura familiar, correspondendo ao grupo que tem renda superior a $30 \mathrm{mil} / \mathrm{ano}$. Segundo o estudo citado, os agricultores puderam acessar tecnologias, incluindo maquinários, assistência técnica, fomento das atividades que elevaram os níveis de produtividade e acesso ao mercado.

De modo geral, entre a amostragem, foi acessado o montante de $\mathrm{R} \$ 141.800,00$, com a média de $\mathrm{R} \$ 9.453,33$ por agricultor. Os valores acessados se dividem entre custeio da produção (80\%), investimento da produção (13\%), e PRONAF Floresta (7\%), movimentando, respectivamente, $\mathrm{R} \$ 68.800,00$, $\mathrm{R} \$ 27.000,00$ e $\mathrm{R} \$ 48.000,00$. O destaque no custeio e investimento foi para a produção de mandioca, seguido da pimenta-do-reino e hortas, e outras atividades, principalmente na fruticultura.

Dos entrevistados, o número de agricultores que acessou o crédito do PRONAF foi de 50\% (15 famílias). Desse quantitativo, em 2018, apenas 4 realizavam as atividades de investimentos na produção por meio do PRONAF. Os acessos ao programa foram a grande maioria em forma de custeio, com um número de 12 estabelecimentos familiares, 2 na categoria de investimento e 1 no PRONAF Floresta.

Do total de feirantes que compõem a amostragem, 56\% (17) são mulheres e 43,3\% (13) são homens. Desse total, apenas 35,3\% (6) das mulheres receberam PRONAF, o restante $(64,7 \%$ ou 11) não acessou. Já entre os homens, desse total, 69,23\% (9) acessaram o PRONAF, e apenas $13,77 \%$ (4) não 
acessou. Assim, pode se verificar que apesar da predominância de mulheres em relação a quantidade feirantes da amostragem, ainda é menor a quantidade de acessos entre as mulheres. Vale destacar nenhuma das entrevistadas informou ter acessado o PRONAF mulher, que é uma das categorias possíveis. Isso corrobora com o estudo de Fernandes:

Partindo de alguns dados estatísticos, se percebeu um índice muito baixo de mulheres que acessavam esse crédito. Conforme observação empírica exploratória realizada em duas regiões de Santa Catarina, se constatou que quanto menos capitalizada for a família, e quanto menor a escolaridade das mulheres, menos acesso elas têm ao crédito. Também foi notório o acesso ao crédito por parte das mulheres que estavam inseridas no Movimento de Mulheres Camponesas. (Fernandes, 2013, p.157).

No caso da pesquisa, realmente as mulheres acessam em menor quantidade o crédito PRONAF. Quando consideramos outras variáveis, de modo geral, as dificuldades de acesso ao crédito dos agricultores ao PRONAF são advindas de múltiplas causas, de ordens organizacionais, burocrática, decisões individuais, prioridades políticas, entre outros fatores. Apesar da complexidade para a compreensão das causas, é possível elencar alguns desses fatores, conforme apresentamos anteriormente. Vale lembrar a sugestão dos autores abaixo:

[...] para serem bem sucedidos, os projetos de assentamentos rurais necessitam de planejamento e estruturação em áreas localizadas em solos férteis, com apoio financeiro na implantação, para a compra de equipamentos e, principalmente, com orientação técnica que forneça o suporte necessário para as atividades produtivas, de agregação de valor e comercialização. Condições essas, que muitas vezes não são contempladas ou apenas parcialmente aplicadas nos projetos já implantados. (Sangalli; Schlindein, 2013, p. 11).

Há casos em que os agricultores decidem não acessar por receio de investirem em suas produções e não obterem o retorno, entrando em ciclo de dívidas. Estudos de Leite e Junior (2015) já identificavam que a decisão em obter financiamento incorpora variáveis não econômicas, onde a conduta moral acaba desestimulando a busca por recursos externos à unidade de produção diante do receio do endividamento.

Para além daqueles que não acessam os créditos por meio do PRONAF, por receio de endividamentos, há aqueles agricultores que conseguem acessar o crédito, entretanto, no momento de implantação do projeto, ocorre o não cumprimento das etapas propostas, que consequentemente acarreta o mau andamento do projeto e até a interrupção do mesmo e, consequentemente, a não concessão de novos créditos (por exemplo, recebeu parte do dinheiro, deu errado e está inadimplente no banco).

Esse é o caso limitante ao crédito do PRONAF por agricultores da AFAFA. A inadimplência em projetos anteriores, em função da falta de ATER para o controle de pragas, onde determinado tipo de doença atacou a cultura que estava sendo implantada, prejudicou a produção. De acordo com alguns interlocutores, apesar de solicitações dos agricultores para receberem visita do técnico responsável pelo projeto, não obtiveram, ocasionado a morte das mudas e a perda dos trabalhos e do investimento (por exemplo, iniciaram o projeto, pragas atacaram a cultura, não obtiveram ATER, e os mesmos interromperam o processo, não pagaram e estão inadimplentes junto ao banco).

Outro aspecto que limita o acesso ao crédito do PRONAF, que foi detectado no decorrer das entrevistas, está relacionado ao fato dos agricultores não conseguirem agregar informações suficientes para pleitear política de fomento à agricultura familiar. Os mesmos conhecem superficialmente as funcionalidades dos programas, e não conhecem bem 
as vias de acesso, como instituições que emitem documentos e até mesmo a preparação de projetos para solicitação de crédito.

Também há os casos daqueles que iniciaram os trâmites para solicitar o crédito, para expansão de suas atividades agrícolas, mas foram indeferidos no início do pedido. O agricultor emitiu a DAP, apresentou projeto, entretanto, durante processo, o banco indeferiu o processo e não deu a devida justificativa, ocasionando no desinteresse do agricultor e desistência.

\section{CONCLUSÃO}

A pesquisa permitiu apresentar o perfil dos associados da Associação de Feirantes da Feira da Agricultura Familiar, bem como da situação de acesso ao crédito PRONAF entre agricultores familiares em questão, por meio de um diagnóstico da situação e indicando os principais limitantes ao acesso.

Como se pode evidenciar, houve quedas significativas nas quantidades de contratos, com uma acentuação maior no município de Abaetetuba quando comparados coma as escalas nacionais e regionais. Entretanto, isso não expressou quedas nas quantidades individuais dos valores empregados por meio da concessão de crédito do PRONAF, no período analisado.

Abaetetuba apresentou uma queda significativa, indo de 526 contratos em 2013, para 66 contratos em 2017, mas os valores médios dos contratos não acompanharam a queda, saindo de pouco mais 4 mil reais para uma média de 18 mil reais, que eventualmente pode ser devido à concessão de novas linhas e categorias de créditos.

Identificamos que 50\% da amostragem obteve acesso ao crédito PRONAF. Entre os fatores que condicionam o acesso ou não acesso ao crédito há algumas predominâncias, principalmente em relação às especificidades dos agricultores e de seus lotes de terra. O primeiro fator identificado, quando separamos em dois grupos, está relacionado ao gênero, já que a maioria de mulheres compõem o universo amostral, mas isso não reflete nas mesmas proporções de acesso ao crédito. Outro aspecto é relacionado ao tamanho das áreas dos agricultores, pois há concentração do grupo de Não-acesso entre aqueles que possuem áreas inferiores a 10 ha. Outro fator condicionante é a posse de documentos, como a DAP.

Sugere-se, como futuros estudos, o aprofundamento na compreensão dos fatores que continuam limitando o acesso às políticas públicas, numa perspectiva comparativa, entre agricultores associados de alguma organização e outros que não são. Isso pode conduzir ao entendimento hipotético de que a consolidação do empreendimento coletivo favorece à adesão às políticas públicas de financiamento.

Além disso, frente ao novo cenário político, que deve reconfigurar os arranjos institucionais e direções das políticas públicas, como os agricultores familiares que atuam nas cadeias curtas podem enfrentar a crescente onda de valorização dos grandes empreendimentos monocultores na região, como dendê e açaí? Por fim, um questionamento fundamental, frente ao momento de incertezas, em 2020, concerne à própria continuidade dos programas de fortalecimento da agricultura familiar.

\section{AGRADECIMENTO}

Aos feirantes da AFAFA. À Universidade Federal do Pará, pela oportunidade de pesquisas.

Todos os autores declararam não haver qualquer potencial conflito de interesses referente a este artigo.

\section{REFERÊNCIAS}


ARAÚJO, J. A.; VIEIRA FILHO, José Eustáquio Ribeiro. Análise dos Impactos do Pronaf na Agricultura do Brasil no Período de 2007 a 2016. Texto para discussão, Rio de Janeiro, n. 2412, set. 2018. Disponível em: <http://repositorio.ipea.gov.br/bitstream/11058/8 696/1/td 2412_.pdf>. Acesso em 28 nov. 2018.

BARROS, B. A "nova classe média" da agricultura familiar. Unisinos online. 2015. Disponível em:<http://www.ihu.unisinos.br/78noticias/540138-a-nova-classe-media-daagricultura-familiar->. Acesso em 03 dez. 2018.

BEZERRA, G. J.; SCHLINDWEIN, M.M. Agricultura familiar como geração de renda e desenvolvimento local: uma análise para Dourados, MS, Brasil. Interações, Campo Grande, v. 18, n. 1, p. 3-15, 2017.

BRASIL. Portaria no 523, de 24 de agosto de 2018. Diário Oficial [da] União [da] República Federativa do Brasil, Casa Civil, Secretaria Especial de Agricultura Familiar e do Desenvolvimento Agrário. Brasília, Edição 165, Seção 1, p. 4. Disponível em:

http://www.imprensanacional.gov.br/materia/-

/asset publisher/Kujrw0TZC2Mb/content/id/3840539 7. Acesso em 30 nov. 2018.

CLAUDINO, L. S. D.; PANTOJA, D.; PIMENTEL, W.; ROSA, J. A Feira da Agricultura Familiar de Abaetetuba, nordeste paraense, como possibilidade ao desenvolvimento (rural) sustentável. Anais do 1. Simpósio Sober Norte, Belém - Pará, 22 e 23 de junho de 2017.

FERNANDES, S. A. Entraves para a inclusão de gênero no Pronaf Mulher no meio rural de Santa Catarina. Revista Grifos, n. 34/35, p. 157-175, 2013.

GRISA, C.; SCHNEIDER, S. Três gerações de políticas públicas para a agricultura familiar e formas de interação entre sociedade e estado no Brasil. Revista de economia e sociologia rural, Piracicaba: SP, v. 52, Suplemento, p. 125-146, 2014.

IBGE - Instituto Brasileiro de Geografia e Estatística. Censo Agropecuário 2017. Dados preliminares. Disponível em: https://censos.ibge.gov.br/agro/2017. Acesso em 29 nov. 2018

LEITE, S. P.; JUNIOR, V. J. W. Estado, políticas públicas e agronegócio no Brasil: revisitando o papel do crédito rural. Revista Pós Ciências Sociais, v. 11, n. 22, p. 83-108, jul./dez. 2014. Disponível em: http: www.periodicoseletronicos.ufma.br/index.php/rpcsoc /article/view/3432/1482. Acesso em: 23 nov. 2018.

SANGALLI, A. R.; SCHLINDWEIN, M. M. Desafios da Agricultura Familiar: Deficiências e Potencialidades de Desenvolvimento no Assentamento Rural Lagoa Grande, Em Dourados, Mato Grosso Do Sul. Revista ORG \& DEMO, Marília, v. 14, n. 2, p. 7-28, jul./dez. 2013.

SCHNEIDER, S.; MATTEI, L.; CAZELLA, A. A. Histórico, caracterização e dinâmica recente do PRONAF- Programa Nacional de Fortalecimento da Agricultura Familiar. In: SCHNEIDER, S.; SILVA, M. K.; MARQUES, P. E. M. (Org.). Políticas Públicas e Participação Social no Brasil Rural, Porto Alegre, p. 21- 50, 2004.

SILVA, S. P. A dinâmica das políticas públicas de desenvolvimento rural e sua incidência territorial: Uma análise do Pronaf no território Vale do Mucuri/MG. Revista Extensão Rural, Santa Maria, v.22, n.2, p. 60-78, 2015. Disponível em: https://periodicos.ufsm.br/extensaorural/article/view/ 13407/pdf 1. Acesso em 29 nov. 2018

SOUZA, C. Políticas Públicas: uma revisão da literatura. Sociologias, Porto Alegre, ano 8, n. 16, p. 20-45, jul./dez 2006 